\title{
Nonoccupational Hearing Loss: A Gift of Urbanization
}

\author{
Sunil Suresh Saler, Parul Sunil Saler, Wilson Desai
}

\begin{abstract}
Noise-induced hearing loss (NIHL) is one of the notifiable occupational disease under legislation related to occupational health and safety of most of the countries of the world. So far risk of exposure to high noise level was considered to be limited to industrial environment only. However, with rapid urbanization and modernization, the cities are becoming crowded as well as noisy. Exposure to noise from these sources have put the population not exposed to industrial noise also at risk of NIHL, especially the younger population. If corrective measures are not taken this may lead to high percentage of younger urban population with permanent hearing loss.

One hundred and fifty students were selected for study which involved questionnaires, interview, routine ENT checkup and audiogram. All the students gave history of exposure to excessive noise from community sources. Two students had residence near railway station while other two stayed near the main highway. It was found that $75 \%$ of them had the habit of listening to music with volume at the peak. A total of $10.7 \%$ students from the group were found to have hearing loss in range of 26 to 42 decibel which is alarming. The nature of hearing loss temporary or permanent is yet to be assessed by repeating the audiogram.
\end{abstract}

Keywords: Hearing loss, Audiogram, Noise, Music player.

How to cite this article: Saler SS, Saler PS, Desai W. Nonoccupational Hearing Loss: A Gift of Urbanization. Int J Head and Neck Surg 2012;3(3):125-126.

Source of support: Nil

Conflict of interest: None

\section{INTRODUCTION}

Noise is derived from Latin word nausea. Noise is defined as unwanted sound, a potential hazard to health and community. Sound, which pleases the listener, is music and that which causes pain and annoyance is noise. At times, what is music for some can be noise for others. Noise is measured by decibel $(\mathrm{dB})$. Twenty $\mathrm{dB}$ is whisper, $40 \mathrm{~dB}$ is quite office, $60 \mathrm{~dB}$ is normal conversation and above $80 \mathrm{~dB}$ the potential to cause damage to hearing loss is increased significantly. ${ }^{1}$ Noise pollution, adversely affect human activity, wild life and damages the physical structure.

The cochlea of inner ear contains hair cells which are responsible for transforming the mechanical energy of vibration received from middle ear into a nerve impulse, which in turn is processed by the human brain and interpreted as sound. Exposure to loud noise leads to destruction of these cells at a much faster rate which may lead to deafness, if corrective actions are not taken.

\section{IMPACT OF NOISE POLLUTION ON HUMAN HEALTH}

Earlier only industrial workers were considered to have risk of developing NIHL. However, with changing lifestyle and use of modern equipments the urban population is exposed to high noise level from various nonindustrial sources. It has been found that the general impact of noise on humans includes the following: ${ }^{2}$

1. Noise-induced hearing loss (NIHL)-temporary, permanent

2. Tiredness and headache

3. Impairment on visual acuity by the presence of loud music

4. Disturbed sleep

5. Elevated blood pressure

6. Loss of appetite

7. Tension and fast talking.

\section{MATERIALS AND METHODS}

One hundred and fifty dental students were selected to form a group for present study. All of them were BDS students studying in Bharti Vidyapeeth Dental College and Hospital Sangli. They were given multiple choice questionnaires which the students were supposed to fill it and were related to use of personal music players, music on mobile phones, Ipods, residence near airport, railways or on roadside. They were interviewed afterward to clarify doubts either of the investigator or the students. All the subjects underwent routine ENT checkup followed by audiometric test. Audiograms of $10.7 \%$ of the subjects (16 students) were found to have hearing loss ranging from 26 to 42 with maximum loss at frequency of $4,000 \mathrm{~Hz}$. This is an indication of NIHL. Loss of hearing due to aging (presbycusis) starts with higher frequency that is $16 \mathrm{kHz}$ and above.

All the 16 affected students gave a history of excessive exposure to noise levels. Twelve students had a habit of listening to loud music and they invariably kept the volume at maximum limit. Two students had their residence near railway station while other two stayed 
near the main highway. The data obtained showed the following:

\begin{tabular}{llc}
\hline Symptoms & Percentage \\
\hline 1. NIHL & 10.7 \\
2. Tiredness and headache & 4 \\
3. Impairment of visual acuity by & \\
& the presence of loud music & 5 \\
4. Elevated blood pressure & 2 \\
5. Impact on sleep & 4 \\
6. Loss of appetite & 10.8 \\
7. & Tension and fast talking & 2.6 \\
\hline
\end{tabular}

\section{DISCUSSION}

The nonindustrial or community sources of noise includes noise from transportation (rail, road or air traffic), loud music from Dolby system and public address system, domestic home appliances and newly added sourcesmobile phone, iPods' and personal music player, play station, etc. In the present generation, students are exposed to noises from community sources like, railroad noise, construction noise, aircraft noise; FM radio, MP3 player with loud music. These students are likely to get noise from dental drills, and other equipments at the college while working with patients. This may lead to increase in threshold shifts. There is a need to create general awareness toward the hazardous effects of noise pollution, particularly in our country.

\section{CONCLUSION}

People generally lack knowledge of the ill effects which noise pollution creates. To avoid NIHL, attention must be given toward the noise around us. Wear adequate hearing protection like foam ear muffs, ear plugs. There will be a definite hearing impairment due to noise pollution which can be either permanent or temporarily, if early precautions are not taken.

\section{REFERENCES}

1. Vogel I, verschure H, Van der Ploeg CP, Brng J, Raat H. Adolescent and Mp3 player, too many risks, too few precaution. Pediatric 2009;123:953.

2. Kumar A, Mathew K, Alexander SA, Kiran C. Output sound pressure levels of personal music systems and their effect on hearing. Noise Health 2010;209:11.

\section{ABOUT THE AUTHORS}

\section{Sunil Suresh Saler (Corresponding Author)}

Professor, Department of Conservative, Bharti Vidyapeeth Dental College, Sangli, Maharashtra, India, e-mail: sunilsaler@indiatimes.com

\section{Parul Sunil Saler}

Assistant Professor, Department of Environment, KIT College of Engineering, Kolhapur, Maharashtra, India

\section{Wilson Desai}

Professor, Department of ENT, Bharti Vidyapeeth Medical College Sangli, Maharashtra, India 